\title{
A health equity lens on government policies
}

A

family doctor leading a new movement to

promote the importance of the social determinants of health is urging the federal government to analyze all its policies, legislation and actions through a health equity lens.

"The only way we're going to make a real difference in people's health is if we have a systematic, system-wide approach for advancing health equity in Canada," said Dr. Ryan Meili, the executive director of Upstream, a nonprofit organization based in Saskatoon.

Meili, who has sought but failed to win the leadership of the New Democratic Party in Saskatchewan, spoke at a oneday conference Upstream organized at the Canadian War Museum in Ottawa on Apr. 3. The conference drew prominent speakers, including Federal Health Minister Dr. Jane Philpott and Sir Michael Marmot, director of the UCL (University College London) Institute of Health Equity in the United Kingdom.

Governments in Finland, South Australia and Quebec have all applied either health-in-all-policies approaches to policy-making or have engaged in health-impact assessments to review their decisions, Meili told the audience of health care professionals, activists and representatives of nongovernmental organizations.

Often, however, those policy approaches are reactive, and have other weaknesses, he said. Even introducing a program that improves overall health, for example, can have the unintended effect of widening health inequities for marginalized populations, such as indigenous Canadians.

"The people who are ready, the people who are already doing well,

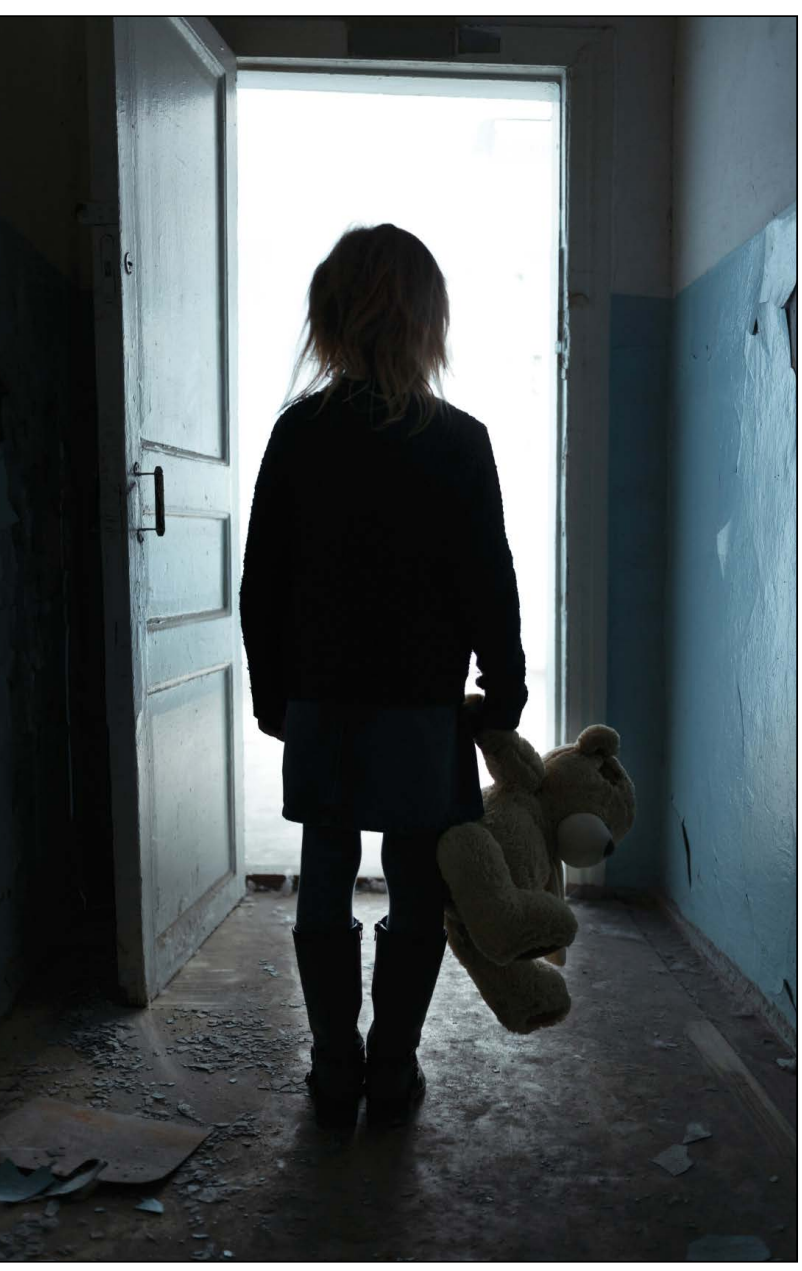

One way to improve health equity is to reduce child poverty rates, which can have a strong impact on children's development and well-being.

will take the most advantage of that program, naturally, and that can actually exacerbate the differences rather than closing the gap, which is what we're trying to do," said Meili.

Upstream's goal is to give voice to "a movement to build a healthy society through people-centred, evidencebased ideas," Meili said. The organization wants to create enough grassroots pressure to get governments to adopt a cabinet-wide, cross-departmental approach to analyzing policy interventions and their outcomes. (Manitoba, for example, has the Healthy Child Committee of Cabinet, on which ministers from every department that could affect children are represented and discuss the outcomes of their decisions.)

Meili encouraged all levels of government to analyze their ongoing work through a Health Equity Action Lens (HEAL) to identify health inequities and the factors that influence them, and then find ways to improve the social determinants of health to close those equity gaps.

Any government that showed leadership in addressing health equity would not only reap political gains, it would have "enormous potential for impact," Meili said.

Philpott, herself a family doctor, embraced the importance of considering the social determinants of health. She "not infrequently" invokes that phrase around the cabinet table on Parliament Hill, along with Indigenous and Northern Affairs Minister Dr. Carolyn Bennett, another physician, Philpott told the conference.

"When I think about health inequity in Canada ... the undeniable gaps and the greatest inequities in health and mental health outcomes are between indigenous and nonindigenous populations of Canadians," she said.

"If we look at rates of suicide and mental health issues and addiction, infectious diseases, noncommunicable diseases, almost every category that you could look at, the gaps are absolutely appalling. The drivers of that again are of course well known - lack of access to quality of education, poverty, social isolation, food security."

The federal government's Mar. 22 budget made an \$8.4-billion investment in education, early childhood development, water, waste water and 
health infrastructure for indigenous Canadians, and that is an example of investing in the social determinants of health, Philpott said.

"The social determinants of health [are] the responsibility of the whole government," she said.

Marmot, who chaired the World Health Organization's Commission on the Social Determinants of Health, stressed the importance of wealth and status in determining health outcomes, as well as the crucial difference that good services, such as early childhood development programs, can make in improving overall health.

"The social circumstances in which children grow up is vitally important to their development," he said. "Reduce poverty; bring the worst off, the most deprived, up towards the average and we'll improve the quality of early child development."

He pointed to tax benefits and transfer payments as examples of policies that governments can enact to reduce child poverty. Sweden, for example, reduced its child poverty rate from $32 \%$ to $12 \%$ after introducing such payments, and Latvia cut its rate from $35 \%$ to $25 \%$.

"Talk about health right across government," said Marmot. "The minister of finance can probably make a bigger difference to children's well-being and development than the minister of health." - Laura Eggertson, Ottawa, Ont.

CMAJ 2016. DOI:10.1503/cmaj.109-5263 